Ciência Florestal, Santa Maria, v. 24, n. 1, p. 211-221, jan.-mar., 2014

ISSN 0103-9954

\title{
EFEITO DA INVERSÃO NO TRATAMENTO DE MOIRÕES SUBMETIDOS AO MÉTODO DE SUBSTITUIÇÃO DA SEIVA
}

\section{EFFECT OF INVERSION ON TREATMENT OF FENCE SUBJECTED TO SAP DISPLACEMENT METHOD}

\author{
Juarez Benigno Paes ${ }^{1}$ Gerlanda Caetano dos Santos ${ }^{2}$ Rafael Rodolfo de Melo ${ }^{3}$ \\ Carlos Roberto de Lima ${ }^{4}$ Wlademir Nicolau Sobrinho ${ }^{5}$
}

\begin{abstract}
RESUMO
O objetivo da pesquisa foi avaliar o efeito da inversão de moirões de algaroba (Prosopis juliflora) e de leucena (Leucaena leucocephala), na solução preservativa, na distribuição, penetração e retenção do borato de cobre cromatado (CCB) aplicado pelo método de substituição da seiva. A algaroba foi coletada na Empresa Brasileira de Pesquisa Agropecuária (EMBRAPA) e a leucena no Campus da Universidade Federal de Campina Grande, em Patos - PB. Foram colhidas árvores com DAP entre 6,0 a 12,0 cm. Retiraram-se dois discos de 2,0 cm de espessura no topo e base das peças. Os discos externos foram descartados e os internos empregados nas determinações das características das madeiras, ficando as peças com 2,0 m. Empregouse uma solução de $2 \%$ de ingredientes ativos de CCB. Foram tratadas 10 peças de cada espécie, tendo cinco delas permanecido dispostas na solução durante 8 dias e cinco tiveram seus topos invertidos após o sexto dia de tratamento. As peças foram secas ao ar, retiraram-se discos de 2,0 cm de espessura para a determinação da penetração (cinco posições nas peças) e para a retenção do CCB (três posições). Os valores das características das madeiras indicaram que as peças eram homogêneas. A absorção da solução foi de 19,9 litros (algaroba) e de 17,0 litros (leucena), acarretando em uma retenção nominal de CCB de 7,72 e $5,34 \mathrm{~kg}$ de ingredientes ativos (i.a.) $/ \mathrm{m}^{3}$, respectivamente. De maneira geral, a inversão das peças na solução preservativa é recomendável, por proporcionar uma melhor distribuição, penetração e retenção do CCB ao longo da peça tratada.
\end{abstract}

Palavras-chave: algaroba; leucena; CCB; substituição de seiva.

\begin{abstract}
This work aimed to evaluate the effect of inversion of Prosopis juliflora and Leucaena leucocephala fence posts, in distribution, penetration and retention of copper chrome borate (CCB) solution applied by sap displacement method. The Prosopis juliflora was collected in Brazilian Agricultural Research Company (EMBRAPA) and the Leucaena leucocephala at the Federal University of Campina Grande in Patos, Paraíba state, Brazil. Trees with DAP from 5.0 to $10.0 \mathrm{~cm}$ were employed. Disks of $2.0 \mathrm{~cm}$ of thickness were retired on the top and on the base of pieces. The external disks were then discarded and the intern ones were employed to determine the wood characteristics, being the round pieces with $2.0 \mathrm{~m}$. A solution of $2 \%$ of active ingredients of CCB was used to treated woods. A total of 10 pieces of each species were treated, and five of them remained in the solution for 8 days and the five ones had their tops inverted after the sixth day of treatment. The pieces were seasoned; disks of $2.0 \mathrm{~cm}$ of thickness were taken in 5 positions

1 Engenheiro Florestal, Dr.,Professor Associado do Departamento de Ciências Florestais e da Madeira, Universidade Federal do Espírito Santo, Av. Governador Lindemberg, 316, Bairro Centro, CEP 29550-000, Jerônimo Monteiro (ES), Brasil. jbp2@uol.com.br

2 Engenheira Florestal, Unidade Acadêmica de Engenharia Florestal, Universidade Federal de Campina Grande, Caixa Postal, 64, CEP 58700-970, Patos (PB), Brasil. gflorestal2@ig.com.br

3 Engenheiro Florestal, Dr., Professor Adjunto da Universidade Federal de Mato Grosso, Instituto de Ciências Agrárias e Ambientais. Av. Alexandre Ferronato, 1200, Distrito Industrial, CEP 78557-267, Sinop (MT), Brasil. rrmelo2@yahoo.com.br

4 Engenheiro Florestal, Dr., Professor Adjunto da Unidade Acadêmica de Engenharia Florestal, Universidade Federal de Campina Grande, Caixa Postal, 64, CEP 58700-970, Patos (PB), Brasil. crlima16@hotmail.com

5 Engenheiro Agrônomo, MSc., Instituto de Terras do Estado da Paraíba, Secretaria de Agricultura do Estado da Paraíba, CEP 58700-000, Patos (PB), Brasil. wlademirsobrinho@ig.com.br

Recebido para publicação em 19/02/2010 e aceito em 10/09/2012
\end{abstract}


along of pieces and the analyses for determination of copper and boron penetration took place. The values of wood characteristics indicated that the pieces were homogeneous. The absorption of the solution was of 19.9 liters (Prosopis juliflora) and of 17.0 liters (Leucaena leucocephala). The nominal retentions of CCB were 7.72 and $5.34 \mathrm{~kg}$ active ingredients (a.i.) $/ \mathrm{m}^{3}$, respectively. In general, the inversion of the pieces in the preservative solution is recommended, by providing a better distribution, penetration and retention of $\mathrm{CCB}$ on treated pieces.

Keywords: Prosopis juliflora; Leucaena leucocephala; CCB; sap displacement method.

\section{INTRODUÇÃO}

A exploração das madeiras nativas resistentes a organismos xilófagos conduziu a escassez das mesmas em várias regiões. Desta forma, o produtor rural passou a utilizar madeiras menos duráveis. Estas espécies, para que apresentem uma boa durabilidade em serviço, necessitam de um tratamento preservativo que lhes forneçam adequada proteção (PAES et al., 2005). A vida útil das madeiras pode ser melhorada por meio de tratamentos simples, sendo também uma forma de proteção dos recursos florestais, que é de fundamental importância ecológica e econômica, pois o alívio da pressão sobre as florestas remanescentes permite a formação de madeiras com maior dimensão, que podem ser utilizadas para fins mais nobres (FARIAS SOBRINHO et al., 2005).

A algaroba (Prosopis juliflora (Sw) D.C.), introduzida no Brasil na década de 1942, é originária da região de Piura, no Peru, ocorre naturalmente em locais de clima semiárido e solos pobres, com rápido crescimento e produz madeira de qualidade para estacas, moirões, lenha e carvão (FARIAS SOBRINHO et al., 2005). Esta espécie apresenta potencial como forrageira, sendo de grande utilidade para a manutenção de rebanho ovino e caprino na Região Nordeste do Brasil.

As árvores de algaroba podem atingir 18 metros de altura e diâmetro de até $80 \mathrm{~cm}$ (SOUZA e TENÓRIO, 1982; AZEVEDO, 1984). Sua madeira é densa e apresenta boas propriedades mecânicas (GOMES, 1999). Além destas características, Karlin e Ayerza (1982) e Gomes (1999) citam que a madeira tem boa textura, grã direita, boa durabilidade natural, sendo indicada para carpintaria e marcenaria.

Apesar das citações de Karlin e Ayerza (1982) e Gomes (1999), quanto à boa resistência natural da madeira de algaroba, Paes et al. (2000) citam que cercas instaladas com essa madeira, em uma fazenda experimental da Empresa Estadual de Pesquisa Agropecuária (EMEPA), no município de Soledade - PB, apresentavam ataques severos de fungos e insetos xilófagos, após o quarto ano de instalação. Além deste fato, Paes et al. (2001) constataram que a madeira de algaroba é severamente atacada por cupins xilófagos em condições de laboratório.

A leucena (Leucaena leucocephala (Lam.) de Wit.) é uma leguminosa originária da América Central. É uma das forrageiras mais promissoras para o semiárido brasileiro, principalmente pela capacidade de rebrota, mesmo durante a época seca, pela adaptação às condições edafoclimáticas do Nordeste brasileiro e pela aceitação por caprinos, ovinos e bovinos (ARAÚJO et al., 2001). Além disto, é utilizada para a recuperação de áreas degradadas, podendo sua madeira ser utilizada para caixotarias para o transporte de frutas e legumes.

Porém, as madeiras de algaroba e de leucena apresentam baixa durabilidade a organismos xilófagos, e necessitam de um tratamento preservativo que lhes confira melhor durabilidade em serviço. Tratar uma madeira é assegurar, por intermédio de produtos químicos (fungicidas e inseticidas), a resistência que não apresenta naturalmente.

Para o tratamento da madeira, há os métodos industriais e os não industriais; entre os não industriais, o de substituição da seiva por transpiração radial se destaca, pelo baixo custo das instalações, podendo ser utilizados equipamentos disponíveis nas propriedades rurais e pela facilidade de se tratar madeiras roliças (HUNT e GARRATT, 1967; FARIAS SOBRINHO et al., 2005).

O método de transpiração radial é recomendado para o tratamento de moirões recém-colhidos com menos de 48 horas entre o corte e o início do tratamento (LEPAGE, 1986). No entanto, Galvão (1968) cita que o intervalo de tempo deve ser até 24 horas após a colheita. Sendo a absorção mais rápida durante os primeiros 2 a 3 dias, diminuindo rapidamente a seguir.

Segundo Lepage (1986), a solução de preservativos hidrossolúveis para ser empregada neste processo deve ter de 2 a $5 \%$ de concentração, a qual 
deve ser posta em um recipiente, até a uma altura mínima de $40 \mathrm{~cm}$, para o tratamento de peças de até 4 metros de comprimento.

O nível da solução preservativa deve ser mantido constante durante o tratamento. Galvão (1968) acrescenta que os moirões devem ser arranjados de forma a permitir uma boa ventilação entre as partes aéreas dos mesmos para acelerar o processo de tratamento. Para evitar que a solução preservativa se evapore, alterando a sua concentração, recomenda-se colocar uma fina camada de óleo sobre a solução, pois assim a seiva evaporada será substituída por uma quantidade semelhante à da solução preservativa (LEPAGE, 1986).

Este processo de tratamento confere uma maior proteção na porção inferior dos moirões, o que é vantajoso, pois é esta a região que ficará em contato com o solo (zona de afloramento em moirões instalados), região mais propícia a ataques de xilófagos (PAES et al., 2005).

A eficácia do tratamento é dependente da penetração, distribuição e retenção do produto preservativo utilizado. A penetração é medida da periferia para o interior da madeira e revela a profundidade da camada tóxica que a protege. Paes et al. (2005) qualificam como boa penetração quando o produto atinge, pelo menos, $10 \mathrm{~mm}$ de profundidade.

A distribuição do preservativo na zona tratada exerce pouca importância na eficiência (HUNT e GARRATT, 1967). Estes autores consideram como critérios para julgar a utilidade de um tratamento a penetração e a quantidade de preservativo absorvido e retido pela madeira.

A retenção é a quantidade de preservativo retida na madeira, sendo o fator mais importante no desempenho do material tratado. Entretanto, a quantidade de produto para fornecer adequada proteção, depende do uso a ser dado à madeira. De modo geral, as retenções mínimas de preservativos hidrossolúveis devem ser de 5 a $16 \mathrm{~kg} / \mathrm{m}^{3}$ (HUNT e GARRATT, 1967). Segundo a Norma Brasileira Regulamentadora - NBR 6232 da Associação Brasileira de Normas Técnicas - ABNT (2013), a retenção, para moirões tratados com $\mathrm{CCB}$, deve ser de, no mínimo, 6,5 kg de ingredientes ativos (i.a.)/ $\mathrm{m}^{3}$ de madeira.

Este estudo visou avaliar o efeito da inversão de peças roliças de algaroba (Prosopis juliflora (Sw) D.C.) e de leucena (Leucaena leucocephala (Lam.) de Wit.), na solução preservativa, na distribuição, penetração e retenção do borato de cobre cromatado (CCB) aplicado pelo método de substituição da seiva.

\section{MATERIAL E MÉTODOS}

\section{Coleta e preparo da madeira}

A madeira de algaroba (Prosopis juliflora (Sw) D.C.) foi coletada no Campo Experimental da Empresa Brasileira de Pesquisas Agropecuária (EMBRAPA) e a de leucena (Leucaena leucocephala (Lam.) de Wit.) no Campus da Universidade Federal de Campina Grande, em Patos - PB. O município de Patos situa-se a $7^{\circ} 1^{\prime}$ de Latitude Sul, a $37^{\circ} 18^{\prime}$ de Longitude Oeste e a 249,09 m de Altitude, apresentando clima quente e seco durante a maior parte do ano.

As árvores foram selecionadas em função do diâmetro a altura do peito (DAP), e utilizadas aquelas com DAP entre 6,0 e 12,0 cm. Após o abate, as peças foram descascadas, identificadas e os diâmetros, tomados no meio do seu comprimento, medidos com fita métrica. A seguir, foram retirados dois discos de 2,0 cm de espessura no topo e base das mesmas. Após a retirada dos discos, as peças ficaram com seu comprimento definitivo de 2,0 metros. Os discos externos foram descartados e os internos empregados nas determinações do teor de umidade (base seca), da densidade básica e da porcentagem de material tratável de cada peça e da absorção de solução preservativa pela madeira.

\section{Preparo da solução preservativa}

Para o preparo da solução preservativa foi utilizado o borato de cobre cromatado (CCB), que é normalmente formulado em base óxida. Segundo a NBR 9480 da ABNT (2009), o CCB tem como princípio ativo o cobre, o cromo e o boro. Sua composição química é especificada como:

- Cromo hexavalente, calculado como $\mathrm{CrO} 3 . . .63,5 \%$

- Boro, calculado como B (elemento)..............10,5\%

- Cobre, calculado como CuO.........................26,0\%

O preservativo foi empregado na concentração $2 \%$ de i.a. A solução foi preparada antes do abate das árvores, para se evitar perdas de umidade das peças durante o preparo da solução. Após o preparo, a solução preservante foi armazenada em um tambor de 200 litros. Desta maneira, empregou-se 
uma solução de mesma concentração, quando da necessidade de reposição.

\section{Tratamento preservativo da madeira}

Para o tratamento, foram empregados três tambores de 200 litros, sendo um como reservatório da solução e nos outros dois as peças foram dispostas verticalmente na solução, tendo-se o cuidado de manter as partes aéreas das mesmas bem separadas. Para cada espécie foram tratadas 10 peças. No tambor, as peças permaneceram parcialmente submersas (50 cm da base), tendo cinco peças de cada espécie permanecido dispostas na solução durante 8 dias e cinco tiveram seus topos invertidos na solução após o sexto dia de tratamento, permanecendo até o oitavo dia.

Para evitar a evaporação e o desbalanceamento da solução preservativa, foram derramados $300 \mathrm{~mL}$ de óleo lubrificante nos tambores de tratamentos. Sempre que necessário, em função da absorção pelas peças, a solução de tratamento foi reposta, para manter constante o seu nível no recipiente e a pressão hidrostática nas peças.

\section{Absorção e retenção nominal do produto preservativo nas madeiras}

Com base nos diâmetros obtidos e nos comprimentos das peças, calculou-se o volume total de madeira empregado em cada tratamento. Do volume total foi subtraído o volume de cerne, obtendo-se o volume e a porcentagem de material tratável de cada peça.

A quantidade adicionada da solução preservativa foi registrada. Com os dados de absorção (litros), de volume de madeira tratável $\left(\mathrm{dm}^{3}\right)$, da concentração da solução preservativa $(2 \%$ de i.a. de CCB) e com base em informações da ABNT (2013), estimou-se a retenção média das peças das espécies.

\section{Secagem e análises químicas das amostras}

Para assegurar uma boa fixação dos sais preservativos na madeira, os moirões tratados foram secos ao ar, durante 60 dias, em local coberto e ventilado. Decorrido o período de secagem, foram executadas as análises químicas para a determinação da penetração do CCB nos moirões tratados. Para tanto, foram retirados discos em cinco posições $(0,10 \mathrm{~m}$ da base, $0,50 \mathrm{~m}$ da base, região mais propícia ao desenvolvimento de xilófagos, 1,00,
1,50 e 1,90 m da base dos moirões), para verificar a distribuição do produto ao longo do comprimento (Figura 1).

As determinações foram feitas por reações colorimétricas. Para as análises, foram seguidas as recomendações da NBR 6232 da ABNT (2013), e um disco de cada posição (Figura 1) serviu para as reações reveladoras do cobre e do boro, em que, após a reação química em um dos lados do disco

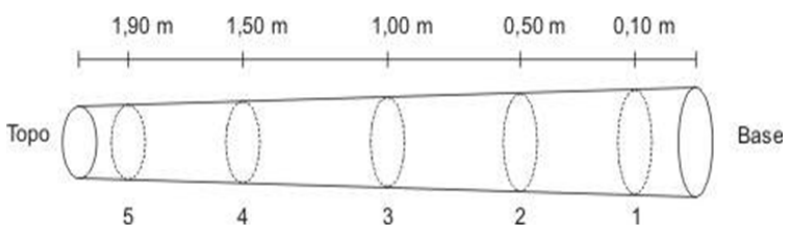

FIGURA 1: Posições no moirão de onde foram retirados os discos para as análises químicas.

FIGURE 1: Positions in fence post where the disks were taken to chemistry analyses.

para o cobre, utilizou-se o lado oposto para as reações do boro.

Para facilitar a leitura e medição da penetração do preservativo, as superfícies dos discos foram lixadas, demarcados ao acaso dois diâmetros perpendiculares entre si, e sobre estes diâmetros, foram realizadas as leituras. A média das leituras de cada disco representou a penetração do elemento químico analisado.

Para a determinação da retenção do $\mathrm{CCB}$ retiraram-se discos suplementares nas Posições 2, 3 e 5 (Figura 1). Nos discos obtidos foram retiradas, em posições diametralmente opostas, quatro amostras de $1,5 \times 1,5 \times 2,0 \mathrm{~cm}$, que receberam codificações de acordo com a posição no disco (Figura 2). Sortearam-se duas das amostras para a análise da retenção ( $\mathrm{kg}$ de i.a. $/ \mathrm{m}^{3}$ de madeira). As amostras foram digeridas, conforme metodologia citada por Paes et al. (2005). As concentrações do cobre e do cromo foram obtidas por espectrometria de absorção atômica e a do boro por colorimetria, conforme descrito por Farias Sobrinho et al. (2005) e Paes et al. (2007). Com os dados das análises químicas e o volume de cada amostra, efetuaram-se os cálculos de retenção, ao empregar a Equação 1 (PAES et al., 2005).

$$
R=\frac{F \times C \times F d \times 10^{3}}{V}
$$


Em que:

$\mathrm{R}=$ Retenção do elemento na madeira $(\mathrm{kg}$ de i.a. $\left./ \mathrm{m}^{3}\right)$;

$\mathrm{F}=$ Fator estequiométrico empregado para a transformação dos elementos químicos para óxidos (cobre x 1,2518 $=\mathrm{CuO}$; cromo x 1,9230 = $\left.\mathrm{CrO}_{3}\right)$

$\mathrm{C}=$ Concentração do elemento químico $(\mathrm{mg} / \mathrm{L})$;

$\mathrm{Fd}=$ Fator de diluição;

$\mathrm{V}=$ volume das amostras de madeira utilizadas nas análises $\left(\mathrm{cm}^{3}\right)$.

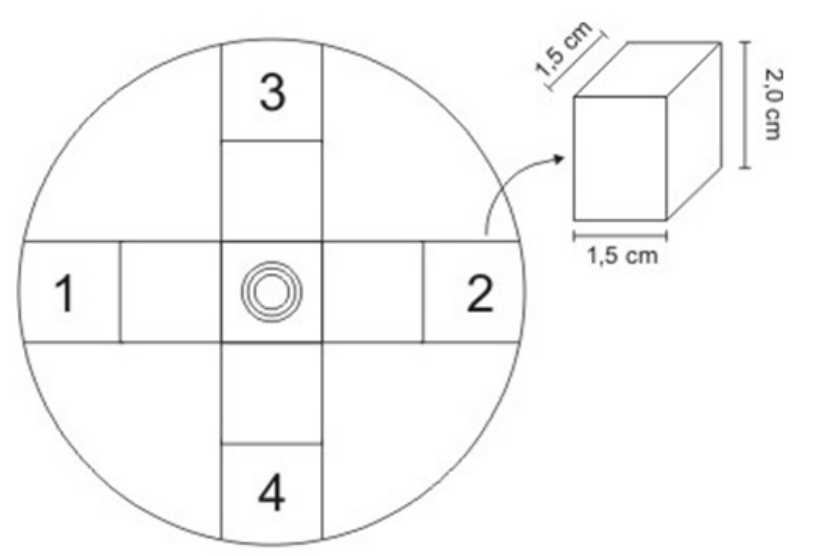

$6,0-12,0 \mathrm{~cm}$

FIGURA 2: Posições nos discos onde foram retiradas as amostras para as análises de retenção.

FIGURE 2: Positions in disks where the samples were taken to the retention analyses.

\section{Delineamento experimental}

Para o tratamento das peças foi utilizado um delineamento inteiramente casualizado com arranjo fatorial, contendo 4 fatores (duas espécies e duas situações de tratamento para cada espécie) e 5 repetições. A penetração de cobre e boro foi avaliada em cinco posições na peça e a retenção do CCB em três posições.

Ao delineamento proposto, foi acrescido o fator posição em que as penetrações ou retenções foram avaliadas. Os resultados foram analisados estatisticamente e os tratamentos e interações detectados como significativos pelo teste de $\mathrm{F}$ tiveram suas médias analisadas pelo teste de Tukey a 5\% de probabilidade.

\section{RESULTADOS E DISCUSSÃO}

\section{Características das madeiras estudadas}

Na Tabela 1 encontram-se as características das madeiras de algaroba (Prosopis juliflora) e leucena (Leucaena leucocephala) tratadas. Os valores médios de teor de umidade da madeira de algaroba submetida às Situações 1 (não invertida) e 2 (invertida) foram próximos, com uma diferença de 2,65\% superior para a Situação 1. Resultado semelhante foi observado para a madeira de leucena, porém, neste caso a diferença foi de $4,26 \%$ superior para a Situação 1. Estes resultados, dentro de cada espécie, indicam que as peças eram homogêneas, por apresentaram diferenças inferiores a $10 \%$, e espera-se que as diferenças encontradas não sejam suficientes para afetarem a absorção da solução preservativa pelas peças de madeira.

A comparação entre o teor de umidade médio para as duas espécies indicou uma diferença de 5,98\% superior para a madeira de leucena. Assim, esta madeira, levando em consideração apenas este parâmetro, apresenta uma maior possibilidade de difusão da solução preservativa nas peças.

Para a densidade, observa-se que as diferenças entre os valores médios das madeiras de algaroba e de leucena foram semelhantes, ou seja, de $0,02 \mathrm{~g} /$ $\mathrm{cm}^{3}$ e de $0,01 \mathrm{~g} / \mathrm{cm}^{3}$, respectivamente. Porém, ao comparar a densidade média das duas espécies, verifica-se que a algaroba apresentou uma densidade superior a da leucena em $0,17 \mathrm{~g} / \mathrm{cm}^{3}$. Este parâmetro faz sugerir que a madeira de leucena apresenta uma maior quantidade de volume de vazios. Salvo outras características, o volume de vazios representa a quantidade de espaços para o fluxo de fluidos, devendo ser a madeira de mais fácil tratabilidade.

Para a espessura média do alburno, a madeira de algaroba apresentou uma diferença de apenas $0,11 \mathrm{~cm}$, e a madeira de leucena $0,08 \mathrm{~cm}$. Isto indica que as madeiras tratadas eram homogêneas. No entanto, a espessura do alburno da madeira de leucena foi superior a da algaroba em $1,18 \mathrm{~cm}$. Portanto, esta madeira apresenta uma maior quantidade de material tratável.

O volume total de madeira submetida aos tratamentos, para ambas as espécies, foram próximos. Isto demonstra que a seleção das peças foi bastante rigorosa. Com relação ao volume tratável para cada espécie, observa-se que a madeira de algaroba submetida à Situação 1 (não invertida) apresentou $1,26 \mathrm{dm}^{3}(5,01 \%)$ a mais que a madeira submetida 
TABELA 1: Características das madeiras de algaroba e leucena tratadas.

TABLE 1: Characteristics of Prosopis juliflora and Leucaena leucocephala treated woods.

\begin{tabular}{|c|c|c|c|c|c|c|}
\hline \multirow[b]{2}{*}{ Situações } & \multicolumn{6}{|c|}{ Madeira de Algaroba } \\
\hline & $\begin{array}{l}\text { Umidade } \\
\text { Média } \\
(\%)\end{array}$ & $\begin{array}{c}\text { Densidade } \\
\text { Básica } \\
\text { Média } \\
\left(\mathrm{g} / \mathrm{cm}^{3}\right) \\
\end{array}$ & $\begin{array}{l}\text { Espessura } \\
\text { Média } \\
\text { Alburno } \\
(\mathrm{cm})\end{array}$ & $\begin{array}{l}\text { Volume } \\
\text { Total } \\
\left(\mathrm{dm}^{3}\right)\end{array}$ & $\begin{array}{c}\text { Volume } \\
\text { Total } \\
\text { Tratável } \\
\left(\mathrm{dm}^{3}\right) \\
\end{array}$ & $\begin{array}{c}\text { Volume } \\
\text { Total } \\
\text { Tratável } \\
(\%) \\
\end{array}$ \\
\hline 1 - Não Invertida & 56,34 & 0,71 & 1,87 & 33,51 & 26,40 & 78,78 \\
\hline 2 - Invertida & 53,69 & 0,73 & 1,76 & 33,79 & 25,14 & 74,40 \\
\hline \multirow[b]{2}{*}{ Situações } & \multicolumn{6}{|c|}{ Madeira de Leucena } \\
\hline & $\begin{array}{l}\text { Umidade } \\
\text { Média } \\
(\%)\end{array}$ & $\begin{array}{c}\text { Densidade } \\
\text { Básica } \\
\text { Média } \\
\left(\mathrm{g} / \mathrm{cm}^{3}\right) \\
\end{array}$ & $\begin{array}{l}\text { Espessura } \\
\text { Média } \\
\text { Alburno } \\
(\mathrm{cm})\end{array}$ & $\begin{array}{l}\text { Volume } \\
\text { Total } \\
\left(\mathrm{dm}^{3}\right)\end{array}$ & $\begin{array}{c}\text { Volume } \\
\text { Total } \\
\text { Tratável } \\
\left(\mathrm{dm}^{3}\right) \\
\end{array}$ & $\begin{array}{c}\text { Volume } \\
\text { Total } \\
\text { Tratável } \\
(\%) \\
\end{array}$ \\
\hline 1 - Não Invertida & 63,13 & 0,55 & 3,04 & 32,06 & 31,90 & 99,50 \\
\hline 2 - Invertida & 58,87 & 0,54 & 2,96 & 32,04 & 31,77 & 99,16 \\
\hline
\end{tabular}

à Situação 2 (invertida). Para a madeira de leucena essa diferença foi de apenas $0,13 \mathrm{dm}^{3}(0,41 \%)$. No entanto, entre as duas espécies a diferença foi de $12,43 \mathrm{dm}^{3}(23,54 \%)$.

\section{Absorções e retenções estimadas nas peças de algaroba e de leucena}

Na Tabela 2 encontram-se os valores de temperaturas $\left({ }^{\circ} \mathrm{C}\right)$, umidades relativas $(\%)$ e absorção da solução preservativa (litros) pelas peças de algaroba e leucena.

Observa-se na Tabela 2 que as temperaturas, durante o período de tratamento foram altas, tendo a menor máxima $\left(29^{\circ} \mathrm{C}\right)$ sido registrada nos dias 29 e 30 de dezembro de 2003 e a maior $\left(32^{\circ} \mathrm{C}\right)$ no período de 23 a 27 . A mínima mais baixa foi de $24^{\circ} \mathrm{C}$, registrada nos dias 30 e 31 , e a maior mínima $\left(27^{\circ} \mathrm{C}\right)$ nos dias 26 e 28 . Estas temperaturas, associadas às baixas umidades relativas apresentadas no período de 23 a 27, favoreceram a evaporação da umidade das peças e promoveram a absorção da solução preservativa pelas mesmas.

A umidade relativa aumentou no período de 28 a 31 (dias com precipitação pluviométrica no final da tarde). $\mathrm{O}$ aumento da umidade relativa provocou uma menor capacidade do ar em receber a umidade contida nas peças.

A absorção total da solução preservativa foi de 19,9 litros (algaroba) e de 17,0 litros (leucena). As peças de algaroba foram postas no tratamento no dia $22 \mathrm{e}$ as de leucena no dia 23. Desta forma, as peças de algaroba ficaram, por mais um dia, em relação às peças de leucena, expostas ao tratamento em condições mais favoráveis à evaporação da umidade presente nas mesmas.

Conforme indicações da ABNT (2013), a madeira tratada para ser utilizada em contado com o solo deve apresentar uma retenção média de $6,5 \mathrm{~kg}$ de i.a. $/ \mathrm{m}^{3}$ de madeira. Como a solução utilizada foi preparada com uma concentração de $2 \%$ de i.a. de CCB, as peças deveriam absorver 325 litros desta solução para atingirem uma retenção nominal de $6,5 \mathrm{~kg}$ de i.a. $/ \mathrm{m}^{3}$, para a densidade da solução considerada igual a $1,0 \mathrm{~g} / \mathrm{cm}^{3}$.

A madeira de algaroba $\left(51,54 \times 10^{-3} \mathrm{~m}^{3}\right)$ deveria absorver 16,75 litros de solução para atingirem $6,5 \mathrm{~kg}$ de i.a. de $\mathrm{CCB} / \mathrm{m}^{3}$. Como esta madeira absorveu 19,90 litros de solução, a mesma ficou com $7,72 \mathrm{~kg}$ de i.a. de CCB. Logo, acima do mínimo preconizado pela ABNT (2013) para madeiras utilizadas em contato com o solo.

O volume de madeira de leucena $\left(63,67 \times 10^{-3} \mathrm{~m}^{3}\right)$ deveria ter absorvido 20,69 litros de solução para atingirem $6,5 \mathrm{~kg}$ de i.a. de $\mathrm{CCB} / \mathrm{m}^{3}$. Como as peças absorveram 17,0 litros, ficaram com $5,34 \mathrm{~kg}$ de i.a. de CCB. Assim, abaixo do mínimo preconizado pela ABNT (2013). Deste modo, as peças de leucena podem ser empregadas em situações diversas, desde que fora do contato com o solo.

\section{Penetração de cobre e boro nas madeiras de algaroba e de leucena}

Na Tabela 3 encontram-se os valores médios de penetrações dos elementos cobre e boro para cada posição nas peças de madeira de algaroba e leucena tratadas. 
TABELA 2: Temperatura $\left({ }^{\circ} \mathrm{C}\right)$, umidade relativa (\%) e absorção da solução preservativa (litros) pelas madeiras de algaroba e leucena.

TABLE 2: Temperature $\left({ }^{\circ} \mathrm{C}\right)$, relative humidity (\%) and absorption of preservative solution (litres) by Prosopis juliflora and Leucaena leucocephala woods.

\begin{tabular}{|c|c|c|c|c|c|c|}
\hline \multirow{2}{*}{$\begin{array}{c}\text { Dezembro } \\
2003 \\
\text { (Dia) }\end{array}$} & \multirow{2}{*}{\multicolumn{2}{|c|}{$\begin{array}{c}\text { Temperaturas } \\
\left({ }^{\circ} \mathrm{C}\right)\end{array}$}} & \multirow{2}{*}{\multicolumn{2}{|c|}{$\begin{array}{l}\text { Umidades Relativas } \\
\qquad(\%)\end{array}$}} & \multicolumn{2}{|c|}{ Absorções (Litros) } \\
\hline & & & & & Algaroba & Leucena \\
\hline \multirow{2}{*}{23} & Máxima & 32 & Máxima & 70 & \multirow{4}{*}{6,4} & \multirow{4}{*}{3,4} \\
\hline & Mínima & 25 & Mínima & 48 & & \\
\hline \multirow{2}{*}{24} & Máxima & 32 & Máxima & 70 & & \\
\hline & Mínima & 25 & Mínima & 48 & & \\
\hline \multirow{2}{*}{25} & Máxima & 32 & Máxima & 70 & \multirow{4}{*}{5,0} & \multirow{4}{*}{5,0} \\
\hline & Mínima & 26 & Mínima & 50 & & \\
\hline \multirow{2}{*}{26} & Máxima & 32 & Máxima & 70 & & \\
\hline & Mínima & 27 & Mínima & 45 & & \\
\hline \multirow{2}{*}{27} & Máxima & 32 & Máxima & 70 & \multirow{4}{*}{4,5} & \multirow{4}{*}{4,2} \\
\hline & Mínima & 26 & Mínima & 50 & & \\
\hline \multirow{2}{*}{28} & Máxima & 31 & Máxima & 93 & & \\
\hline & Mínima & 27 & Mínima & 60 & & \\
\hline \multirow{2}{*}{29} & Máxima & 29 & Máxima & 93 & \multirow{2}{*}{3,0} & \multirow{2}{*}{1,6} \\
\hline & Mínima & 25 & Mínima & 65 & & \\
\hline \multirow{2}{*}{30} & Máxima & 29 & Máxima & 88 & \multirow{2}{*}{1,0} & \multirow{2}{*}{1,2} \\
\hline & Mínima & 24 & Mínima & 58 & & \\
\hline \multirow{2}{*}{31} & Máxima & 30 & Máxima & 80 & & \multirow{2}{*}{1,6} \\
\hline & Mínima & 24 & Mínima & 55 & & \\
\hline & & Tot: & & & 19,9 & 17,0 \\
\hline
\end{tabular}

TABELA 3: Valores médios de penetração de cobre e boro $(\mathrm{mm})$ nas peças de algaroba (Prosopis juliflora) e leucena (Leucaena leucocephala).

TABLE 3: Average values of cupper and boron penetration (mm) in Prosopis juliflora and Leucaena leucocephala pieces.

\begin{tabular}{ccccccc}
\hline \multirow{2}{*}{ Espécies } & \multirow{2}{*}{ Situações } & \multicolumn{5}{c}{ Penetração de Cobre $(\mathrm{mm})$ em cada Posição nas Peças } \\
\cline { 3 - 7 } Algaroba & Não Invertida & 13,60 & 5,65 & 5,55 & 3 & 5 \\
& Invertida & 12,50 & 6,35 & 5,65 & 3,36 & 4,95 \\
\multirow{2}{*}{ Leucena } & Não Invertida & 17,50 & 2,45 & 0,45 & 0,25 & 7,03 \\
& Invertida & 15,60 & 1,95 & 0,81 & 1,71 & 1,11 \\
\hline \multirow{2}{*}{ Espécies } & Situações & \multicolumn{5}{c}{ Penetração de Boro $(\mathrm{mm})$ em cada Posição nas Peças } \\
\cline { 3 - 7 } Algaroba & Não Invertida & 14,05 & 12,55 & 12,05 & 10,60 & 10,45 \\
& Invertida & 15,80 & 12,75 & 13,90 & 11,40 & 12,25 \\
\multirow{2}{*}{ Leucena } & Não Invertida & 16,05 & 10,85 & 8,10 & 4,50 & 1,90 \\
& Invertida & 14,80 & 10,40 & 7,70 & 6,50 & 4,40 \\
\hline
\end{tabular}


Para as madeiras de algaroba e leucena, independente do tratamento a que as peças foram submetidas, observa-se que a penetração de cobre, para as Posições 2, 3, 4 e 5 (Figura 1), foi insuficiente para fornecer às madeiras um tratamento adequado. Esta constatação está de acordo com Farias Sobrinho et al. (2005), Paes et al. (2005) e Paes et al. (2007); que consideram como insuficientes penetrações inferiores a $10 \mathrm{~mm}$.

Os valores de penetração do boro na madeira de algaroba foram superiores ao mínimo recomendado pelos autores anteriormente citados. Já para a leucena, as penetrações nas Posições 3, 4 e 5 foram inferiores ao recomendado. Paes et al. (2007) ao tratarem peças roliças de leucena pelo método de substituição de seiva obtiveram valores de penetração do boro superiores aos encontrados, para todas as posições analisadas. Por outro lado, os valores de penetração do cobre, na Posição 1 , foram inferiores aos encontrados nesta pesquisa.

Para a madeira de algaroba, Farias Sobrinho et al. (2005) obtiveram valores semelhantes aos encontrados, provavelmente em função das condições do local de tratamento terem sido semelhantes. Os maiores valores de penetração, encontrados por Paes et al. (2007), para a madeira de leucena, podem estar relacionados às condições climáticas no período de tratamento, bem como a uma melhor ventilação oferecida pelo local de tratamento. Quanto maior a ven- tilação, maior a evaporação da seiva e, consequentemente, maior a absorção da solução preservativa.

Os dados que originaram a Tabela 3 foram analisados estatisticamente. Para o cobre e boro, observou-se que a posição, espécie e a interação entre a posição e espécie foram significativas pelo teste de F. No entanto, para o boro, além desses fatores, a situação e a interação entre posição e situação foram significativas. A interação entre posição e espécie (cobre e boro) e entre posição e situação (boro) foram desdobradas e analisadas pelo teste de Tukey a $5 \%$ de probabilidade (Tabela 4 ).

Para o cobre, observou-se que a penetração na madeira de algaroba foi superior à da madeira de leucena, exceto para a Posição 1. A análise, dentro de cada espécie, indicou que a penetração na Posição 1 foi superior a das demais, as quais não diferiram estatisticamente.

Observa-se para o boro, que a maior penetração na madeira de algaroba foi atingida na Posição 1, a qual diferiu das penetrações alcançada nas Posições 4 e 5. As penetrações nas Posições 2 e 3 apresentaram valores intermediários entre as Posições 1,4 e 5.

Para a leucena, a penetração na Posição 1 foi superior às demais. Tendo a Posição 2 apresentado a segunda maior penetração, a qual diferiu das Posições 4 e 5 . Ao comparar as duas espécies em cada posição analisada, observou-se que a penetração na algaroba

TABELA 4: Comparações entre médias para a penetração $(\mathrm{mm})$ de cobre e boro nas peças de madeira. TABLE 4: Comparisons among averages to penetration $(\mathrm{mm})$ of copper and boron in the wood pieces.

\begin{tabular}{|c|c|c|c|c|c|}
\hline \multicolumn{6}{|c|}{ Penetração de Cobre (mm) } \\
\hline \multirow{2}{*}{ Espécies } & \multicolumn{5}{|c|}{ Posições nas Peças } \\
\hline & 1 & 2 & 3 & 4 & 5 \\
\hline 1 - Algaroba & $12,88 \mathrm{Ab}$ & $6,00 \mathrm{Ba}$ & $5,60 \mathrm{Ba}$ & $4,58 \mathrm{Ba}$ & $5,99 \mathrm{Ba}$ \\
\hline 2 - Leucena & $16,55 \mathrm{Aa}$ & $2,20 \mathrm{Bb}$ & $0,63 \mathrm{Bb}$ & $0,98 \mathrm{Bb}$ & $0,93 \mathrm{Bb}$ \\
\hline \multicolumn{6}{|c|}{ Penetração de Boro (mm) } \\
\hline \multirow{2}{*}{ Espécies } & \multicolumn{5}{|c|}{ Posições nas Peças } \\
\hline & 1 & 2 & 3 & 4 & 5 \\
\hline 1 - Algaroba & $15,93 \mathrm{Aa}$ & $12,65 \mathrm{ABa}$ & $12,98 \mathrm{ABa}$ & $11,00 \mathrm{Ba}$ & $11,35 \mathrm{Ba}$ \\
\hline 2 - Leucena & $15,43 \mathrm{Aa}$ & $10,63 \mathrm{Ba}$ & $7,90 \mathrm{BCb}$ & $5,50 \mathrm{CDb}$ & $4,15 \mathrm{Db}$ \\
\hline \multirow{2}{*}{ Situações } & \multicolumn{5}{|c|}{ Posições nas Peças } \\
\hline & 1 & 2 & 3 & 4 & 5 \\
\hline 1 - Não Invertida & $16,05 \mathrm{Aa}$ & $11,70 \mathrm{Ba}$ & $10,07 \mathrm{BCa}$ & 7,55 CDa & $6,18 \mathrm{Db}$ \\
\hline 2 - Invertida & $15,30 \mathrm{Aa}$ & $11,58 \mathrm{ABa}$ & $10,80 \mathrm{Ba}$ & $8,95 \mathrm{Ba}$ & $9,33 \mathrm{Ba}$ \\
\hline
\end{tabular}

As médias seguidas por uma mesma letra maiúscula, na horizontal, ou minúscula, na vertical, não diferem estatisticamente (Tukey, $\mathrm{p} \geq 0,05$ ). 
nas Posições 2, 3, 4 e 5 foram superiores às obtidas pela madeira de leucena.

A comparação entre as situações indicou que a inversão das peças na solução preservativa não favoreceu a penetração, fornecendo resultados superiores nas peças não invertidas na solução, apenas para a Posição 5 (topo das peças). No entanto, no tratamento em que as peças foram invertidas, mesmo tendo apresentado uma penetração numericamente inferior na Posição 1, quando comparado ao tratamento em que as peças não foram invertidas, a diferença não foi o suficiente para ser significativa estatisticamente.

A penetração do boro foi mais homogênea ao longo das peças invertidas na solução preservativa. Apesar de não ser observada diferença estatística entre as situações invertida e não invertida para a penetração do cobre, e como o boro se distribuiu de forma mais homogênea nas peças invertidas, proporcionando uma maior penetração no topo das mesmas e ainda a parte aérea de peças instaladas no solo estarem mais susceptível ao ataque de insetos, a inversão das peças é recomendável, em função da maior proteção das peças em relação àquelas não invertidas na solução preservativa.

\section{Retenções de soluções preservativas nas peças de algaroba e de leucena}

Na Tabela 5 estão apresentadas as retenções médias de CCB ( $\mathrm{kg}$ de i.a. $\left./ \mathrm{m}^{3}\right)$ nas madeiras de al- garoba e leucena e uma comparação entre os valores da retenção real, obtidos por meio de amostragem nos discos, situações e posições avaliadas, com o emprego de análises químicas e a retenção nominal média de cada espécie, calculada com base nas absorções da solução pelas peças durante o tratamento.

Observa-se, na Tabela 5, que foram obtidas retenções superiores à mínima recomendada pela ABNT (2013) na Posição 2 (linha de afloramento em moirões instalados no solo) nas madeiras de algaroba (invertida e não invertida) e de leucena (não invertida). Para a madeira de algaroba, ainda foram observadas retenções satisfatórias, para todas as posições, quando as peças foram invertidas na solução preservativa. Isto indica que a inversão das peças proporcionou uma melhor distribuição do produto preservativo ao longo das peças, fato já observado quando da discussão dos valores de penetração (Tabela 3).

As retenções obtidas foram inferiores às estimadas. As diferenças podem estar associadas às dificuldades em medir as absorções pelas peças em função do diâmetro dos barris, do sistema de amostragens (retenção verdadeira) em que apenas três peças foram utilizadas e pela retenção de cobre, cromo e boro, em amostras provenientes da base das peças (Posição 1, Figura 1) não terem sido avaliadas.

A porção entre as Posições 1 e 2 (Figura 1), por permanecerem em contato com a solução

TABELA 5: Comparação entre as retenções médias de CCB $\left(\mathrm{kg}\right.$ i.a. $\left./ \mathrm{m}^{3}\right)$ obtidas e estimadas para as madeiras de algaroba e leucena,

TABLE 5: Comparison among average retentions of CCB $\left(\mathrm{kg}\right.$ a.i. $\left./ \mathrm{m}^{3}\right)$ obtained and estimated to Prosopis juliflora and Leucaena leucocephala woods.

\begin{tabular}{|c|c|c|c|c|c|c|}
\hline \multirow{2}{*}{ Espécies } & \multirow{2}{*}{ Situações } & \multirow{2}{*}{ Posições } & \multicolumn{4}{|c|}{ Retenção Média de CCB (kg i.a. $/ \mathrm{m}^{3}$ ) } \\
\hline & & & Discos & Peças & Obtidas & Estimadas \\
\hline \multirow{6}{*}{ Algaroba } & & 2 (Base) & 6,50 & & \multirow{6}{*}{6,49} & \multirow{6}{*}{7,72} \\
\hline & Não Invertida & 3 (Meio) & 3,62 & 4,66 & & \\
\hline & & 5 (Тopo) & 3,87 & & & \\
\hline & \multirow{3}{*}{ Invertida } & 2 (Base) & 7,91 & & & \\
\hline & & 3 (Meio) & 6,72 & 8,31 & & \\
\hline & & 5 (Тopo) & 10,30 & & & \\
\hline \multirow{6}{*}{ Leucena } & \multirow{3}{*}{ Não Invertida } & 2 (Base) & 8,37 & & \multirow{6}{*}{3,72} & \multirow{6}{*}{5,34} \\
\hline & & 3 (Meio) & 2,23 & 3,92 & & \\
\hline & & 5 (Тopo) & 1,17 & & & \\
\hline & \multirow{3}{*}{ Invertida } & 2 (Base) & 5,03 & & & \\
\hline & & 3 (Meio) & 1,48 & 3,52 & & \\
\hline & & 5 (Тopo) & 4,05 & & & \\
\hline
\end{tabular}


preservativa, absorve uma maior quantidade de produtos. Isto ocorre em virtude da porção inferior permanecer submersa na solução preservativa. Desta forma, o preservativo penetra na madeira pela parte inferior e alcança a parte superior por capilaridade. Como este processo é irregular, a parte inferior da peça é a primeira a translocar a água, absorvendo antes o preservativo, é natural que a porção entre as Posições 1 e 2 (base da peça) tenha mais produto que as demais. Resultados semelhantes foram observados por Farias Sobrinho et al. (2005), Paes et al. (2005) e Torres et al. (2011).

Em função da baixa absorção da solução preservativa pelas peças de leucena, recomenda-se que o tratamento seja executado em locais mais ventilados e em dias mais secos, com o objetivo de promover uma maior penetração da solução nas peças.

Os valores de retenção obtidos $(\mathrm{kg}$ de i.a. $\left./ \mathrm{m}^{3}\right)$, que deram origem às médias apresentadas na Tabela 5, foram analisados estatisticamente. Os fatores posição, espécie e as interações entre posição e situação e entre situação e espécies foram significativas. As interações foram desdobradas e as médias analisadas pelo teste de Tukey a $5 \%$ de probabilidade (Tabela 6).

A análise do efeito da situação em cada posição na peça (Tabela 6) revelou que as peças não invertidas apresentaram uma maior retenção

TABELA 6: Comparações entre médias para a retenção de $\mathrm{CCB}\left(\mathrm{kg}\right.$ de i.a. $\left./ \mathrm{m}^{3}\right)$ nas madeiras de algaroba e leucena.

TABLE 6: Comparisons among averages to retention of CCB ( $\mathrm{kg}$ of a.i. $\left./ \mathrm{m}^{3}\right)$ in Prosopis juliflora and Leucaena leucocephala woods.

\begin{tabular}{cccc}
\hline \multicolumn{4}{c}{ Retenção de CCB $\left(\mathrm{kg} / \mathrm{m}^{3}\right)$} \\
\hline \multirow{2}{*}{ Situações } & \multicolumn{3}{c}{ Posições nas Peças } \\
\cline { 2 - 4 } & 2 (Base) & 3 (meio) & 5 (Topo) \\
\hline 1 - Não Invertida & $7,44 \mathrm{Aa}$ & $2,93 \mathrm{Ba}$ & $2,52 \mathrm{Bb}$ \\
2 - Invertida & $6,47 \mathrm{Aa}$ & $4,10 \mathrm{Aa}$ & $7,18 \mathrm{Aa}$ \\
\hline \multirow{2}{*}{ Situações } & \multicolumn{2}{c}{ Espécies de Madeira } \\
\cline { 2 - 4 } & 1 - Algaroba & 2 - Leucena \\
\hline 1 - Não Invertida & $4,66 \mathrm{Ab}$ & $3,92 \mathrm{Aa}$ \\
2 - Invertida & 8,31 Aa & $3,52 \mathrm{Ba}$ \\
\hline
\end{tabular}

As médias seguidas por uma mesma letra maiúscula, na horizontal, ou minúscula, na vertical, não diferem estatisticamente (Tukey, $\mathrm{p} \geq 0,05$ ). na Posição 2 (50 cm da base das peças), enquanto para as peças invertidas, a retenção foi semelhante para todas as posições.

Dentro de cada posição, observou-se diferença significativa apenas para o topo (Posição 5) em que as peças invertidas apresentaram uma maior retenção que as não invertidas. Isto indica que a inversão das peças na solução preservativa proporciona uma melhor proteção à madeira, fato já firmado por Farias Sobrinho et al. (2005), Paes et al. (2005), Paes et al. (2007) e Torres et al. (2011).

Observa-se, para a situação em que as peças não foram invertidas na solução preservativa, que tanto a algaroba quanto a leucena apresentaram retenções semelhantes. Por outro lado, para a situação em que as peças foram invertidas na solução, as peças de algaroba tiveram uma maior retenção. Para a algaroba, a retenção foi maior nas peças invertidas na solução preservativa. Entretanto, para a leucena não se observou diferenças nas retenções das peças invertidas e não invertidas.

Em função da baixa absorção da solução preservativa pelas peças de leucena, recomenda-se que o tratamento seja executado em locais mais ventilados, com o objetivo de promover uma maior penetração da solução.

\section{CONCLUSÕES}

As características apresentadas pelas madeiras de algaroba e leucena, como umidade, espessura do alburno e porcentagem de madeira tratável, favorecem a penetração e difusão dos produtos preservativos para o interior da madeira.

A baixa absorção da solução preservativa pela madeira de leucena pode ter sido influenciada pelas condições de tratamento, principalmente no que diz respeito à ventilação do ambiente e às condições atmosféricas reinantes.

A retenção nominal nas peças de algaroba foi superior à mínima recomendável para madeiras a serem utilizadas em contato com o solo.

A penetração do cobre foi baixa para as madeiras de algaroba e leucena, tornando-as susceptíveis ao ataque de fungos apodrecedores no caso de rachadura das peças.

Em função da baixa absorção, penetração e retenção do $\mathrm{CCB}$, as peças de leucena não estariam aptas a serem utilizadas em contato com o solo.

A inversão da madeira na solução preservativa proporcionou uma maior penetração de boro no topo das peças de leucena. 
De maneira geral, a inversão das peças na solução preservativa é recomendável, por proporcionar uma melhor distribuição, penetração e retenção do CCB ao longo da peça tratada.

\section{REFERÊNCIAS BIBLIOGRÁFICAS}

ARAÚJO, G. G. L.; ALBUQUERQUE, S. G.; GUIMARÃES FILHO, C. Opções no uso de forrageiras arbustivo-arbóreas na alimentação animal no Semi-árido do Nordeste. In: CARVALHO, M. M.; ALVIN, M. J.; CARNEIRO, J.C. (Eds.). Sistemas agroflorestais pecuários: opções de sustentabilidade para áreas tropicais e subtropicais. Juiz de Fora: FAO/EMBRAPA, 2001, cap. 6, p. 111 - 137.

ASSOCIAÇÃO BRASILEIRA DE NORMAS TÉCNICAS. NBR 9480: peças roliças preservadas de eucalipto para construções rurais - requisitos. Rio de Janeiro, 2009.12 p.

ASSOCIAÇÃO BRASILEIRA DE NORMAS TÉCNICAS. NBR 6232: penetração e retenção de preservativos em madeira tratada sob pressão. Rio de Janeiro, 2013. 16 p.

AZEVEDO, N. V. As mil e uma utilidades da algaroba. Ciência Hoje, Rio de Janeiro, v. 3, n. 13, p. 24 - 24, 1984.

FARIAS SOBRINHO, D. W.; PAES, J. B.; FURTADO, D. A. Tratamento preservativo da madeira de algaroba (Prosopis juliflora (Sw) D.C.), pelo método de substituição de seiva. Cerne, Lavras, v. 11, n. 3, p. 225 - 236, 2005.

GALVÃO,A.P. M. Características da distribuição de alguns preservativos hidrossolúveis em moirões de Eucalyptus alba Reinw. tratados pelo processo de absorção por transpiração radial. Piracicaba. 1968. 115 f. Tese (Doutorado em Agronomia) Universidade de São Paulo, Escola Superior de Agricultura Luiz de Queiroz, Piracicaba, 1968.

GOMES, J. J. Características tecnológicas da algarobeira (Prosopis juliflora D.C.): contribuição para seu uso racional. 1999. 118 f. Dissertação (Mestrado em Engenharia Agrícola) -
Universidade Federal da Paraíba, Campina Grande, 1999.

HUNT, G. M; GARRAT, G. A. Wood preservation. 3rd ed. New York: McGraw Hill, 1967, 433 p.

KARLIN, U. O.; AYERZA, H. R. O programa da algaroba na República Argentina. In: SIMPÓSIO BRASILEIRO SOBRE ALGAROBA, 1., 1982, Natal. Anais... Natal: EMPARN, 1982. p. 146-197. LEPAGE, E. S. Preservativos e sistemas preservativos. In: LEPAGE, E.S. (Coord.). Manual de preservação de madeiras. São Paulo: IPT, 1986, v.1, p. 279-342.

PAES, J. B.; LIMA, C. R.; SANTOS, J. M. Tratamento preservativo de moirões de algaroba (Prosopis juliflora D.C.) pelo método de Boucherie modificado. In: ENCONTRO BRASILEIRO EM MADEIRAS E EM ESTRUTURAS DE MADEIRA, 7., 2000, São Carlos. Anais... São Carlos: USP/EESC, 2000. 1 CD-ROM.

PAES, J. B.; MORAIS, V. M.; LIMA, C. R. Resistência natural de nove madeiras do semiárido brasileiro a cupins subterrâneos, em ensaio de preferência alimentar. Brasil Florestal, Brasília, v. 20, n. 72, p. $59-69,2001$.

PAES, J. B.; et al. Tratamento preservativo de peças roliças de leucena (Leucaena leucocephala (Lam.) de Wit.) pelo método de substituição da seiva. Revista de Ciências Agrárias, Belém, n. 47, p. 231-246, 2007.

PAES, J. B.; MORESCHI, J. C.; LELLES, J. G. Avaliação do tratamento preservativo de moirões de Eucalyptus viminalis Lab. e de bracatinga (Mimosa scabrella Benth.) pelo método de substituição de seiva. Ciência Florestal, Santa Maria, v. 15, n. 1, p. 75-86, 2005.

SOUZA, R. F.; TENÓRIO, Z. Potencialidades da algaroba no Nordeste. In: SIMPÓSIO BRASILEIRO SOBRE ALGAROBA, 1., 1982, Natal. Anais... Natal: EMPARN, 1982. p. 198 - 216.

TORRES, P. M. A.; et al. Tratamento preservativo da madeira juvenil de Eucalyptus camaldulensis Dehnh. pelo método de substituição de seiva. Cerne, Lavras, v. 17, n. 2, p. 275-282, 2011. 